\title{
Sediment transport in sewers: the Cesarina combined sewer network
}

\author{
G. Silvagni ${ }^{1}$, F. Volpi ${ }^{1}$ \& R. Celestini ${ }^{2}$ \\ ${ }^{I}$ Department of Civil Engineering and Computer Science Engineering, \\ University of Rome Tor Vergata, Italy \\ ${ }^{2}$ Acea Ato2 S.p.A., Italy
}

\begin{abstract}
The polluting effects of storm water runoff on the receiving waterbodies represent an increasingly relevant problem in developing urban areas. In combined sewer pipes, transiting flood waves cause the alternation of sediment erosion and deposition of the solid material transported by the flow. Combined sewer deposit, mainly generated as an effect of such phenomena during the dry weather period between two rain events, is generally a mix of sand and highly polluting materials. Accumulation of sediments along a combined sewer network is often the cause of dysfunctions in the drainage system itself and negative impacts on the quality of receiving waters, due to the resuspension and overflow of pollutants. Both aspects have been investigated for the combined sewer of Rome thanks to an experimental catchment of about 2800 ha in the Cesarina $\mathrm{S}$. Basilio area. Based on the simulations conducted, structural solutions were proposed and evaluated, aimed at reducing the operational and environmental problems related to sewer sediment. The results show noticeable margins for the optimisation of the whole sewer system and for the reduction of its environmental impact.

Keywords: combined sewage, sewer sediments, transport model, water quality.
\end{abstract}

\section{Introduction}

The millenary history of the sewer network of Rome has its origins in the early Roman period, when the first great channels discharging in the Tiber were built to drain the local territory, characterised by the alternation of hills and lowlands. 
With the development of the city during the Roman Empire and the Middle Ages, the network was progressively integrated with large drainage pipes conveying groundwater and domestic discharges to the river, whose selftreatment capacity was sufficient to ensure the sanitary and hygienic protection of the urban centre. As the city followed its growth, the initial network of channels became the framework for the modern sewer system.

In its current configuration, the sewer system of Rome is divided in four main basins (Figure 1). The main sewer branches essentially follow the original water courses, tributaries of the city rivers Tiber and Aniene, and convey sewage to the four major wastewater treatment plants (WWTPs) holding a global capacity of about 3,100,000 PE. Except for the coastal Ostia basin, the other three are drained by combined sewers whose primary pipes still generally maintain the large sections and high capacity typical of the ancient channels.

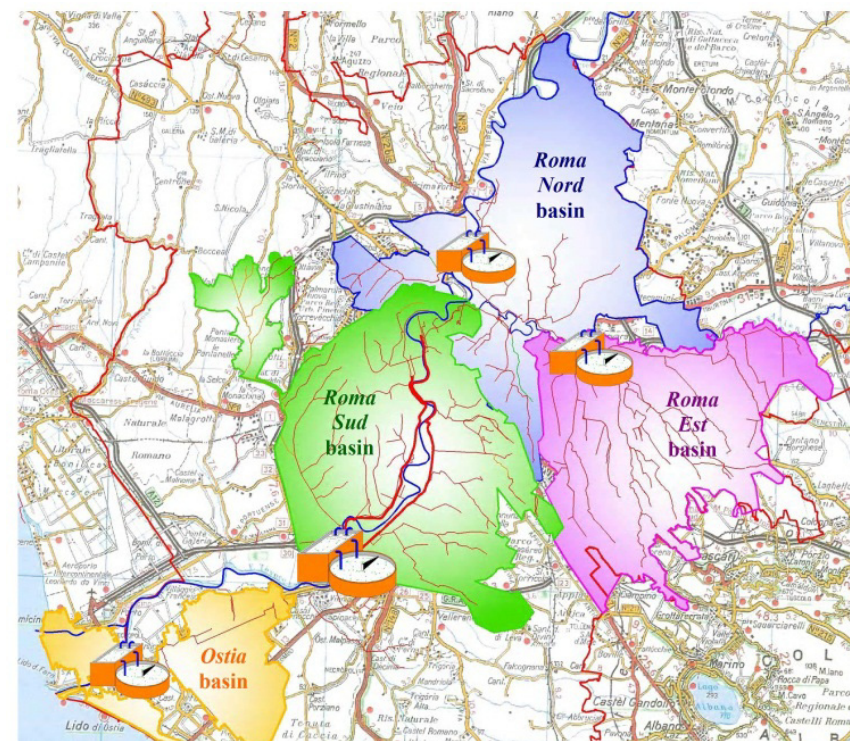

Figure 1: The main sewer basins in Rome.

During wet weather, a series of combined sewer overflow (CSO) structures, distributed along the network, allow the discharge towards local water bodies of the storm water volume exceeding WWTP capacity; CSO design criteria ensure that discharges fulfill the Italian environmental legislation in terms of domestic wastewater dilution. The terminal sewer pipes close to the rivers are characterized by low gradients, large sizes and either egg-shaped or rectangular cross-sections. Their flow-lines are often at a comparable height to the ordinary flood levels in nearby water bodies. With particular reference to the urban area around the river Aniene, extraordinary floods have occasionally resulted in water flowing back from the river to the sewers through CSO structures. 
Given this background, it is evident how one of the frequent problems observed in the described terminal branches is the presence of solid deposit, sometimes built up to such an extent that the local sewer functionality is affected (Figure 2).

As well as holding polluting potential in itself, solid material in combined wastewater also represents a means for the conveyance of pollutants attached to the solid particles [1-5]. A portion of approximately 30\% of settleable solids consists of organic matter, biomass growing on pipe walls (slime), of which $80 \%$ is characterised by an average settling velocity of $0.0028 \mathrm{~cm} / \mathrm{s}$.

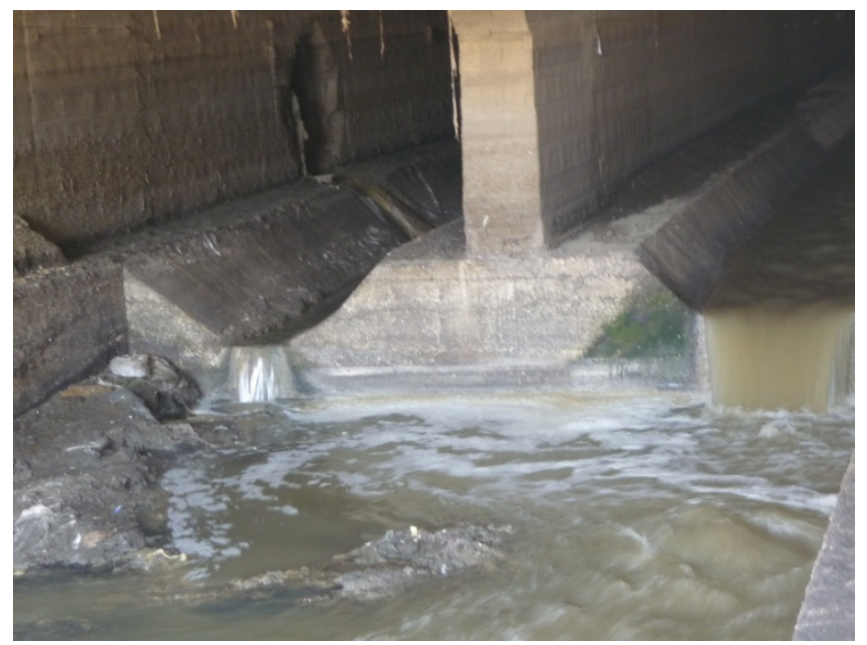

Figure 2: Example of deposit in a CSO chamber.

Furthermore, owing to the chemical complexation reactions occurring in such high-humidity environments, the slime typically contains heavy metals and organic micro-pollutants transported by runoff and adsorbed on to its particles.

The main sources of heavy metals in urban basins are: tyre and road surface wear, vehicles, wash-off of impermeable surfaces and green areas, as well as solid material transported by natural streams and artificial canals entering the sewer system. The latter case is particularly frequent in Rome, where the urban development in the last century and the increasing use of natural streams as receptors for domestic discharges induced their progressive connection to the city sewer system. The direct consequence was a change in nature and an increase in quantity of the solid material transported by combined sewers during wet weather (Figure 3). The major issues concerning the presence of deposit within sewers are functional (blockages, damage to inline electromechanical devices), structural (abrasion of internal walls) and sanitary/environmental (potential CSO discharge during rain events).

In the last few years, the problems connected to solid transport during wet weather and to its potential impact on receiving bodies have been investigated in the "Cesarina - San Basilio" experimental catchment, located north-east of 
Rome city centre, within the sewer basin of "Roma Nord" WWTP. The terminal branches of its sewer network, leading to a main CSO structure nearby the river Aniene, are affected by nearly permanent solid deposits, denoting the local vulnerability of the system, with potential environmental impact in case of sudden wash-off through CSO discharge.
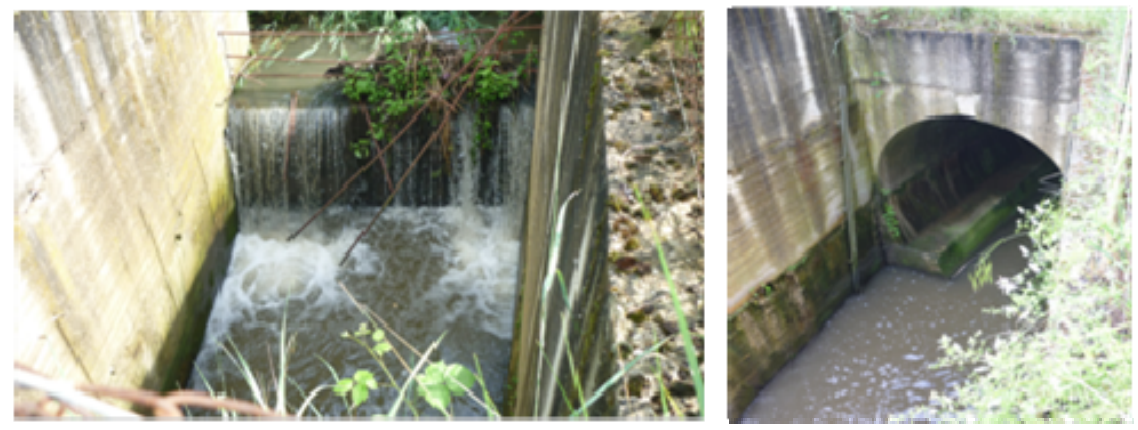

Figure 3: Cesarina stream - inlet to combined sewer.

\section{The "Cesarina - San Basilio" catchment}

The surface globally drained by the "Cesarina - San Basilio" sewer system extends for 2,800 ha, comprising over 100,000 inhabitants. It is essentially divided in a lower urban sub-basin, whose average elevation is about $40 \mathrm{~m}$ a.s.1., and an upper natural one, with an elevation of $100 \mathrm{~m}$ a.s.l. The urban fabric is heterogeneous, including both highly populated districts and low-density residential areas. The sewer system is divided in two main gravity sub-networks, joined in their terminal section leading to the common CSO chamber.

The Cesarina sub-network drains the largest 2015 ha area, of which 1850 ha consist of a natural basin which hosts the Cesarina and Cecchina streams, while the remaining part coincides with the densely populated Cecchina district.

The San Basilio sub-network extends over 760 ha and reflects the same subdivision into an upper 360 ha natural basin, drained by the homonymous stream, and a lower urbanised portion enclosing the San Basilio, Rebibbia and Ponte Mammolo districts.

The Cesarina network has been equipped since 2006 with a metering station installed along its terminal egg-shaped sewer pipe, providing water depth and quality monitoring data during wet weather. Throughout the years, further hydraulic and water quality monitoring has also been performed for the storm flow coming from the Cesarina stream. Furthermore, specific tests have been conducted on the nature and quality of the solid sediment found both in the downstream CSO chamber and by the major upper stream inlets.

In particular, Figure 4, which represents the particle size distributions for the sediment beds at both the stream inlets and the CSO chamber, shows how $\mathrm{d}_{50}$ changes, respectively, from 1.0 to $0.5 \mathrm{~mm}$. A great proportion of the solid samples consists of sand, with a content of inorganic matter ranging from $80 \%$ to 
$90 \%$; the sample from the CSO chamber contains a higher quantity of silt, whose origin is to be found in the domestic discharge and in the solid settlement occurring during the occasional river backflow events.
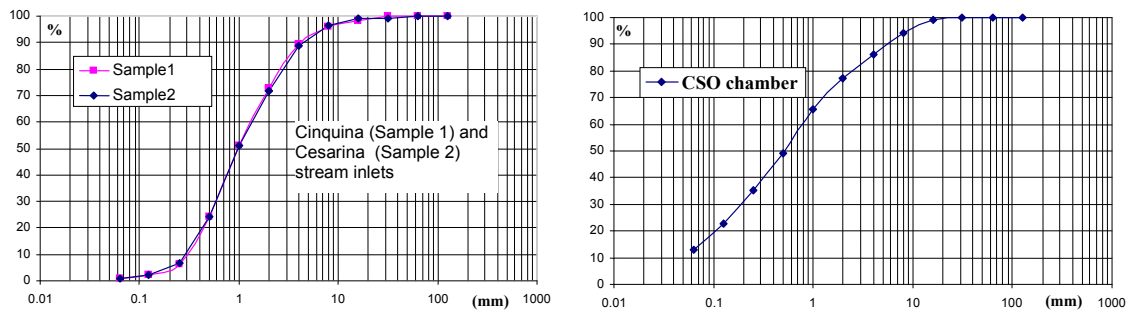

Figure 4: Particle size distributions for sediment bed at Cesarina sites.

Based on the comparison of particle size distributions, on water quality data and on direct observation, it was concluded that most of the sediment accumulated at the CSO chamber and along the terminal branch of the Cesarina sewer pipe comes from the upper natural sub-basins. However, the presence of heavy metals, although in modest concentrations, highlights the definite concurrence of urban runoff to the sedimentation process.

Water quality monitoring during significant storm events, analysed from 2007 onward, reported recurrent high peaks of TSS and COD concentrations in the corresponding load waves, while concentrations of Total Phosphorus, Nitrogen compounds and heavy metals generally remained within thresholds suitable for direct CSO discharge [6].

Problems related to the presence of sediment in the described sewer system, as well as the frequent occurrence of high TSS concentration peaks in local runoff, raised the need for a deeper understanding of the system's behaviour through the definition of a hydraulic and solid-transport model. The objective was the evaluation of possible structural or operational interventions, such as the introduction of silt traps at the stream inlets and/or the use of the terminal sewer pipes for inline sedimentation.

\section{Hydraulic and solid-transport modelling}

The creation of the experimental catchment's model started from the collection of detailed geometrical and typological information for the whole main network, through the study of original designs and statistical and geographical data. Thanks to specific surveys, such information was verified and completed. The software Infoworks $C S^{\circledR}$ (Innovyze ${ }^{\circledR}, H R$ Wallingford) was chosen for its implementation and for the simulation of gradually varied flow (Figures 5 and 6) [7-9]. The hydraulic model was then calibrated based on the set of data collected by the monitoring stations as well as on a dedicated series of direct measurements (Figures 7 and 8).

In Figure 8 the observed and simulated water depths at the terminal eggshaped sewer pipe of the Cesarina network are compared for the storm event 


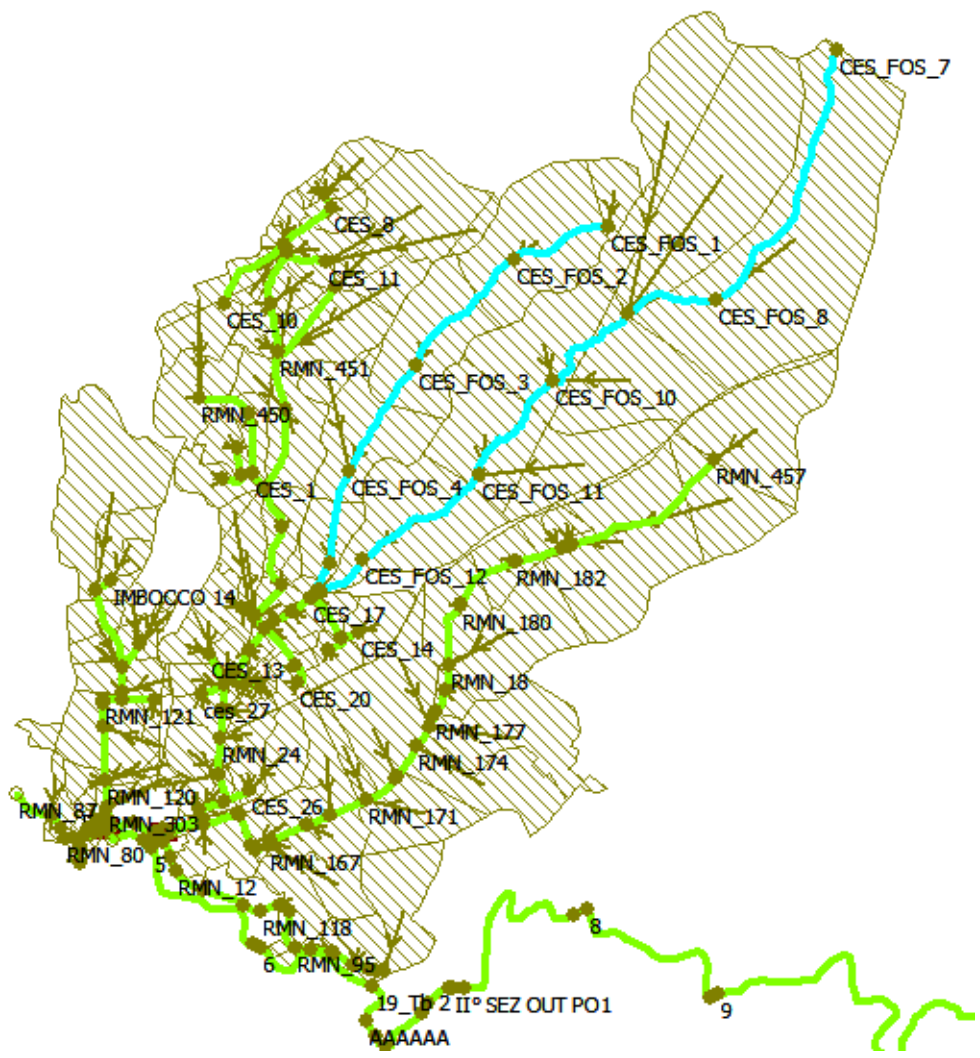

Figure 5: Cesarina and San Basilio catchment model.

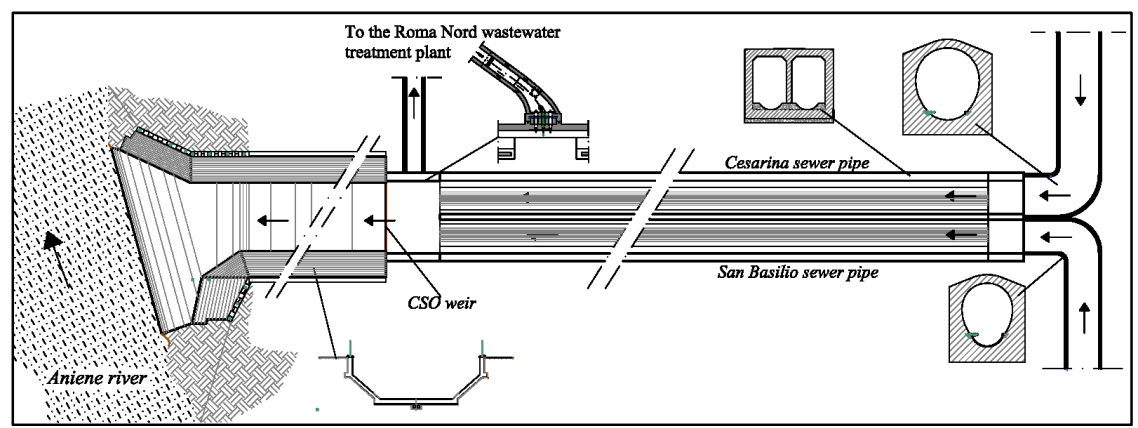

Figure 6: Cesarina's terminal pipe and CSO chamber - schematic plan. 


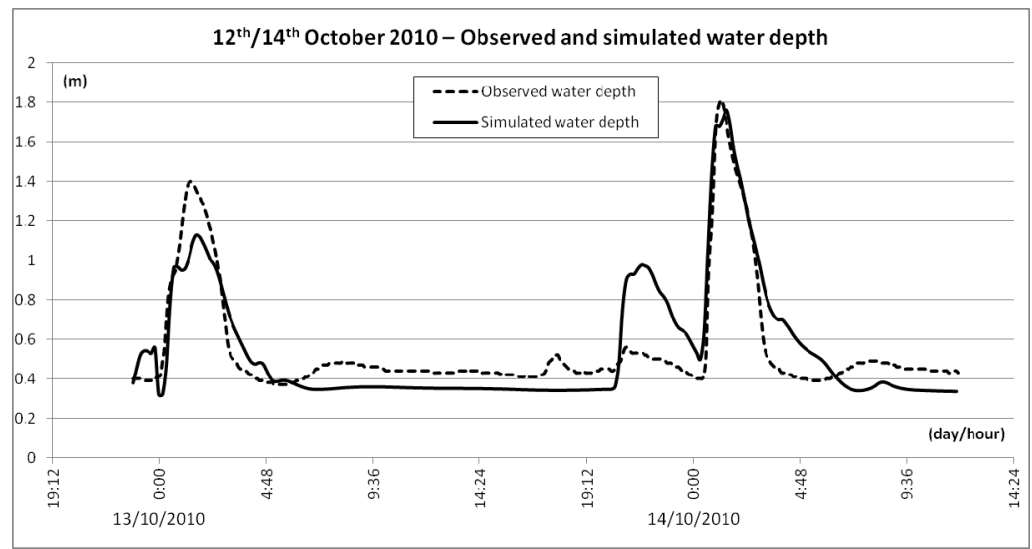

Figure 7: 12th/14th October 2010 - observed and simulated water depth at Cesarina terminal pipe.

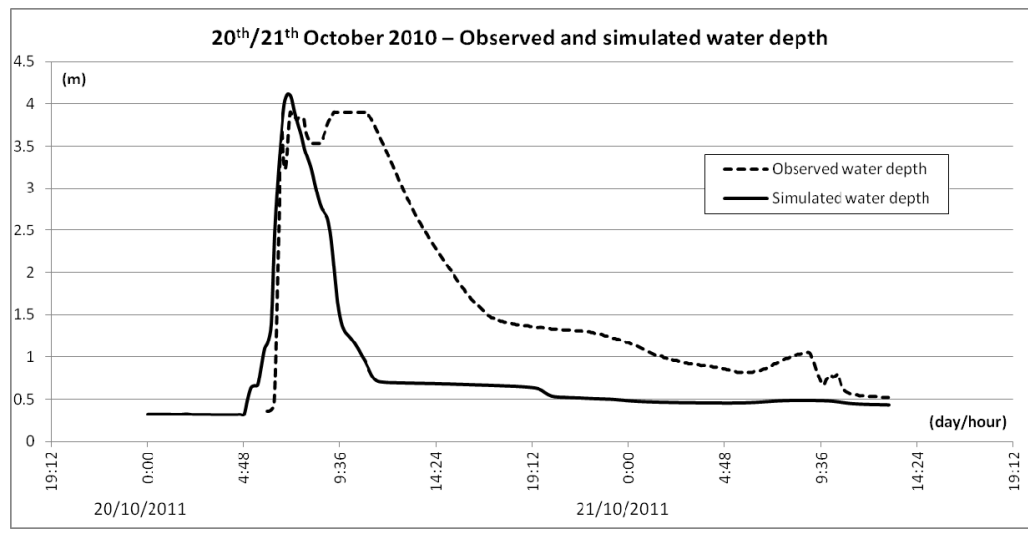

Figure 8: 20th/21st October 2011 - observed and simulated water depth at Cesarina terminal pipe.

registered on 20th October 2011. This particular event, characterized by diffusedly intense and persistent rain, generated momentary flood events all over the city, as well as the raise of the river Aniene's level. Although the simulation of the hydraulic interaction with the river is not the model's objective, the consequent backflow of the Aniene above the CSO weir is still evident when looking at the observed water depth in the graph, which shows a second peak at around 9:00, completely absent in the simulated pattern. The river filled the local pipe capacity for the duration of the flood, about 6 hours.

Over an observation period of a year (October 2010-October 2011), five significant storm events have been analysed. Based on the simulations performed and on the experimental water quality data collected, the respective cumulative polluting load curves have been drawn to represent the intensity of the first flush effect (Figures 9-13). 


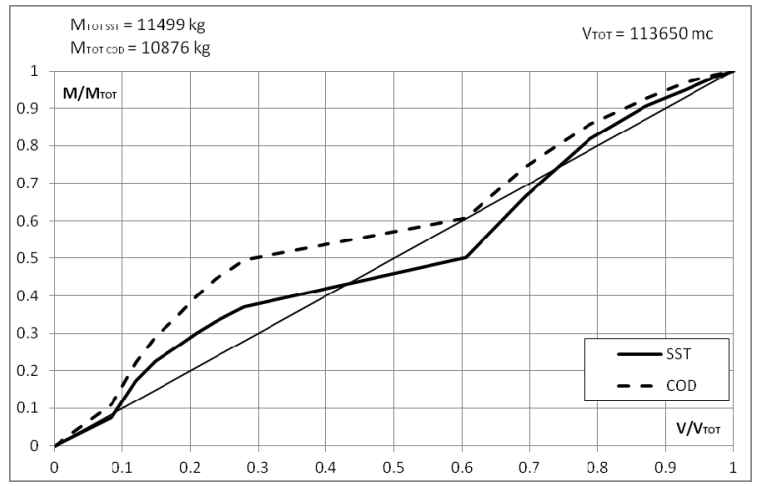

Figure 9: 12th/14th October 2010 - cumulative TSS and COD load curves.

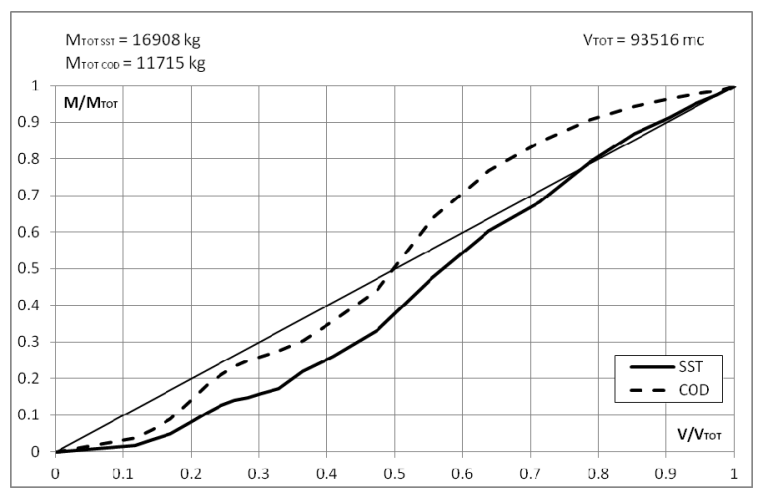

Figure 10: 16th February 2011 - cumulative TSS and COD load curves.

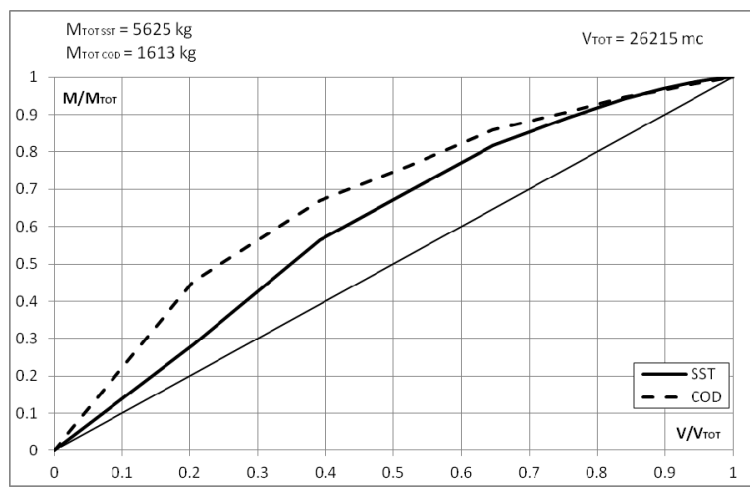

Figure 11: 5th July 2011- cumulative TSS and COD load curves. 


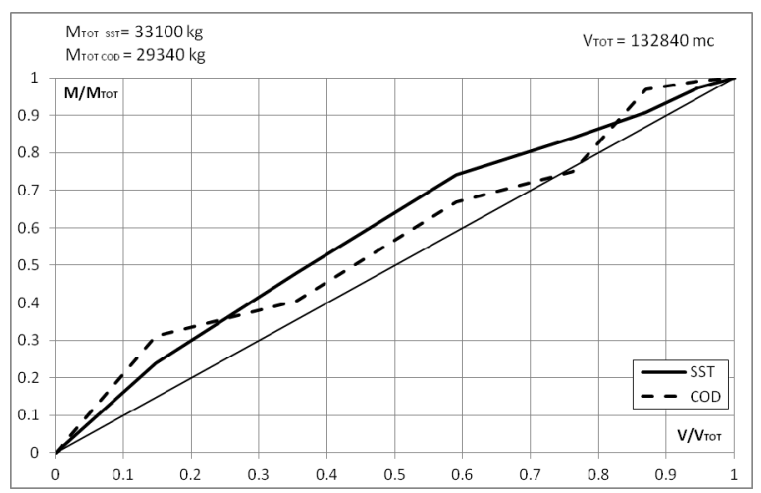

Figure 12: 19th Sept. 2011 - cumulative TSS and COD load curves.

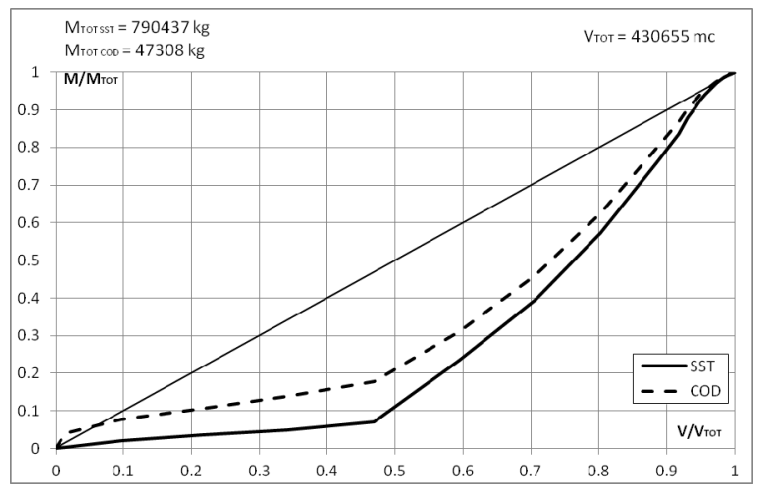

Figure 13: 20th/21st October 2011 - cumulative TSS and COD load curves.

In Figures 11 and 12, referring to the storm events occurred, respectively, on the $5^{\text {th }}$ July and $19^{\text {th }}$ September 2011, the typical first-flush pattern of TSS curves appears evident, although not particularly intense. For the other storm events, however, the first-flush effect is essentially nonexistent and the load waves are in phase with the corresponding hydrograms. For the exceptional storm event that occurred on $20^{\text {th }}$ October 2011, a definite last-flush pattern was registered, mostly due to the fact that on that occasion high-intensity rainfall affected the upper natural basin more than the lower urban area, accentuating the nature of runoff more typical of the former.

In Italy, most regional public administrations have adopted, in recent years, environmental legislations which in different ways impose or favour the temporary storage of fixed water volumes from the initial stage of storm waves. The aim is the reduction of the pollutant load discharged by CSOs by a significant proportion of the whole mass transported by storm water runoff, thanks to the storage and treatment of a far smaller proportion of such water. The experimental basis of this method mostly relates to a series of studies conducted 
on small- to mid-sized urban catchments [10,11]. It is evident, however, how the same method does not offer similar effects on large urban basins such as the Cesarina: referring to the graphs in Figures 9-12, the reduction of $70 \%$ in TSS load would require the storage of water volumes ranging from $19,000 \mathrm{~m}^{3}\left(5^{\text {th }}\right.$ July 2011) to $93,000 \mathrm{~m}^{3}$ ( $19^{\text {th }}$ September 2011).

A storage tank of a similar capacity for the Cesarina catchment, located near the existing CSO chamber, is hardly feasible within the local urban fabric.

Therefore, alternative solutions have been studied aimed at using the online storage capacity of the drainage system and at reducing runoff pollution by sedimentation [2-5]. In particular, the selected option points at separating solid matter of natural origin from the urban one by building silt traps at the main inlets of the local streams. In addition, the dynamic use of the whole network capacity for the sewer system of Rome is being tested, exploiting its large and low-gradient pipes and offering the possibility to actively control inline sedimentation.

In order to quantify the potential benefits generated by the introduction of silt traps at all the main sites where natural streams enter the combined sewer, simulations of the solid transport phenomenon were run for the different rain events, considering the presence of traps designed for rainfall of 2-5 years return time. The following figures show some simulation results comparing the amount of solid material cumulatively transported at the final sewer section with and without silt traps (Figures 14-16).

The simulations show how the potential introduction of silt traps could averagely reduce the solid material transported throughout the storm events by $30 \%$. This would imply noticeable operational benefits by decreasing the maintenance needed to remove sediment at the CSO chamber, as well as environmental benefits by mitigating the discussed impact of sediment wash-off and discharge during intense rainfall.

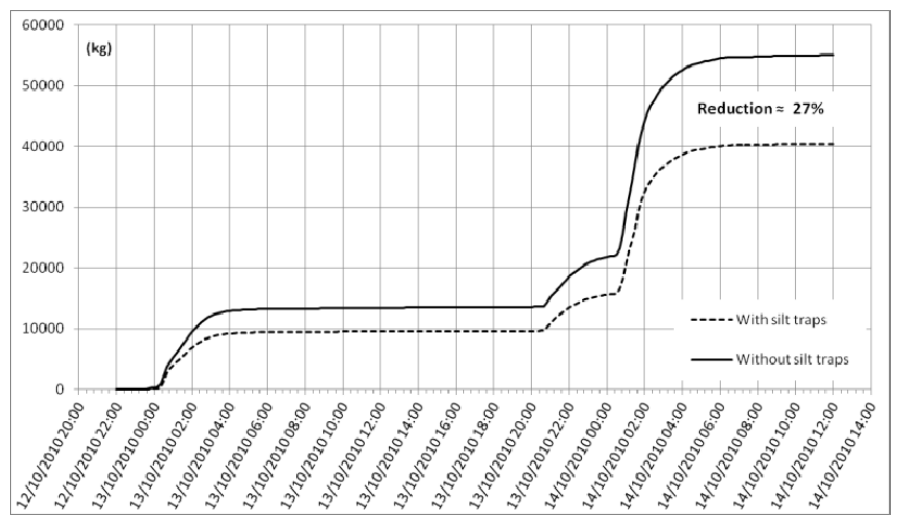

Figure 14: 13th-14th October 2010 - terminal section of Cesarina pipe material cumulatively transported by flow with/without silt traps. 


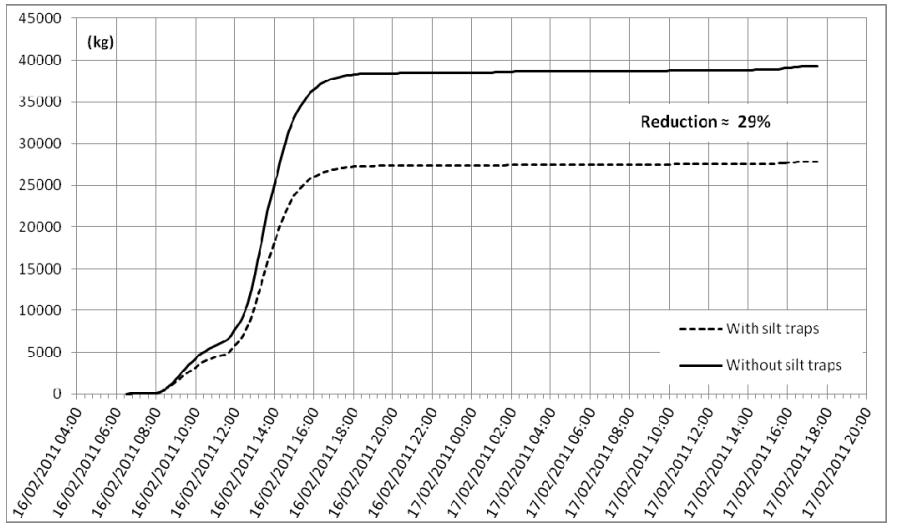

Figure 15: 16th February 2011 - terminal section of Cesarina pipe - material cumulatively transported by flow with/without silt traps.

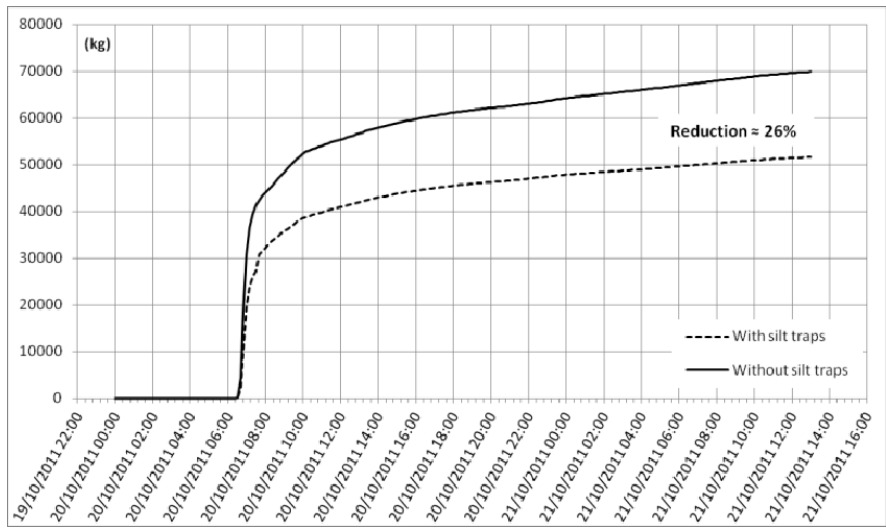

Figure 16: 20th/21st October 2011 - terminal section of Cesarina pipe material cumulatively transported by flow with/without silt traps.

As mentioned above, real time control techniques to dynamically manage storm water volumes along the whole sewer network are being studied in the same pilot catchment; a further step in this direction would be adapting such control techniques and using movable hydraulic devices in order to exploit the large terminal sewer channels for regulated inline sedimentation. Such an approach would bring about the benefits of proactive maintenance, but it would also require the periodical cleaning of large amounts of sediment, with higher costs connected with their removal and disposal. 


\section{Conclusions}

The Cesarina - San Basilio network is a typical example of the Rome sewer system, characterized by large terminal pipes with low gradients and egg-shaped or rectangular cross-sections. The presence of permanent sediments represents an operational and environmental issue, with a potential negative impact on the quality of receiving waters linked to the wash-off and CSO discharge of the solids during wet weather.

The study of solid transport for the Cesarina runoff allowed the characterisation of storm waves. In particular, hydraulic and quality monitoring registered at the terminal sewer section of the pilot catchment showed a typical runoff with limited first-flush intensity and hydrograms essentially in phase with their pollutant load curves. This particular aspect implies the need to store storm volumes up to $90,000 \mathrm{~m}^{3}$ to ensure the hypothetical reduction of globally discharged solid material by $70 \%$.

Because of the effective unfeasibility of storage tanks with such capacity in the local urban fabric, a hydraulic and solid transport model of the whole sewer network was used to evaluate alternative solutions, such as the direct removal of the portion of solid material in wastewater coming from the natural sub-basins. This would be achieved by means of several silt traps to be built at the sewer nodes which receive natural streams.

Simulation results show a consequent potential 30\% reduction in the solid material cumulatively transported through the terminal Cesarina sewer channel, with obvious operational benefits and a mitigated environmental impact.

As the option of dynamic capacity control of the whole sewer network is currently being evaluated for the same pilot catchment, in the future this will offer the possibility to consider the use of movable hydraulic devices to exploit the large low-gradient pipes for regulated inline sedimentation.

\section{References}

[1] Michelbach, S., Origin, Resuspension and settling characteristics of solids transported in combined sewage. Water Science Technology, 31(7), pp. 69-76, 1995.

[2] Lee, H. \& Bang, W., Characterization of urban stormwater runoff. Water Science Technology, 3(7), pp. 1773-1780, 2000.

[3] Gromaire-Mertz, M. C., Chebbo, G. \& Saah, M., Origins and characteristics of urban wet weather pollution in combined sewer system: the experimental urban catchment "Le Marais" in Paris. Water Science Technology, 37(1), pp. 35-43, 1998.

[4] Gromaire-Mertz, M. C., Garnaud, S., Gonzalez, A. \& Chebbo, G., Characterization of urban runoff pollution in Paris. Water Science Technology, 39(2), pp. 1-8, 1999.

[5] Chebbo, G., The transfer of solids in combined sewer networks. Water Science Technology, 31(7), pp. 95-103, 1995. 
[6] Presidenza della Repupplica Italiana. Decreto Legislativo 03/04/2006 n. 152 e s.m.i.. Norme in Materia Ambientale. http://www.camera.it/ parlam/leggi/deleghe/06152dl.htm.

[7] Celestini, R., Silvagni, G., Spizzirri, M. \& Volpi, F., Sediment Transport in sewers. Water Resource Management IV, ed. C.A. Brebbia and A.G. Kungolos, WIT press: UK, pp 273-282, 2007

[8] Celestini, R., Silvagni, G. \& F. Volpi, Transport of solid material in sewer pipe - The sample catchment of Cesarina (Rome). Proc. of the 32nd Congress of IAHR, July 1-6, 2007.

[9] Wallingford Software, Infoworks CS - Network Modelling Software. http://www.innovyze.com/products/infoworks_cs/.

[10] Artina, S., Maglionico, M., Dimensionamento di vasche di prima pioggia secondo criteri di "stream standard". II Conferenza Nazionale sul Drenaggio Urbano, Palermo (IT), May 10-12, 2000.

[11] Ciaponi, C., Papiri, S., Todeschini, S., Vasche di prima pioggia: analisi critica di possibili modalità di svuotamento. $I^{\text {st }}$ Convegno Nazionale di Idraulica Urbana “Acqua e città", Sant'Agnello (NA, IT), 2005. 